\title{
Public goods and the value of product quality regulations: the case of food safety
}

\author{
Stephen F. Hamilton ${ }^{\mathrm{a}}$, David L. Sunding ${ }^{\mathrm{b}}$, David Zilberman ${ }^{\mathrm{b}}$ \\ a 23 Economics Building, University of Arizona, Tucson, AZ 85721, USA \\ ' 207 Giannini Hall, University of California, Berkeley, CA 94720, USA
}

\begin{abstract}
The paper examines preferences for product quality regulations. Our premise is that preferences for product quality regulations derive from preferences for both private and public goods. The model is used to explain public attitudes toward a referendum measure to eliminate pesticide residues on food. Results from a survey of consumers are consistent with the conceptual model and show that preferences for public goods influence support for the product quality regulation. The results help explain why consumption behavior is a poor predictor of political behavior, and have implications for methods that use voting and market behavior to value public goods.
\end{abstract}

Keywords: Voting choice, Consumer behavior; Public goods

\section{Introduction}

Product quality regulations have attracted considerable attention as a topic of public concern and have emerged as a major policy question in the United States and elsewhere. A prime example of this emphasis is the successful effort to secure passage of the Food Quality Protection Act of 1996, legislation that addresses food 
quality by, among other measures, reducing the amount of pesticide residue allowed on fresh and processed foods.

Our premise is that product quality regulations can affect consumer welfare in four ways. The most obvious effects of such regulations are to increase market prices and to increase the provision of some desirable attribute of the product. For example, product quality regulations are sometimes designed to reduce the incidence of injury, as in the case of mandated safety standards such as childproof caps on medication, protective packaging, infant car seats, flame-retardant fabric, and airbag requirements. These interventions reduce risk and increase the consumer's level of health.

Third, product quality regulation may provide affiliated public goods. These public goods are especially affected by regulations directed at production methods. For example, a regulation that requires tuna to be caught in a 'dolphin-safe' manner enhances environmental quality. Altruism may also be important in product quality decisions, as evidenced by the recent effort by manufacturers such as Nike, Reebok and K-Mart to ensure consumers that their products are made without the use of child or sweatshop labor. Indeed, product quality regulation need not have any effect on consumptive characteristics at all: for instance, 'dolphin-safe' tuna tastes no different than conventional tuna, but may be more valued by consumers nonetheless.

Finally, product quality regulation that restricts choice in the marketplace can result in a loss of options to consumers. Product quality regulations tend to change slowly over time - once enacted, they are unlikely to be repealed anytime soon since the transaction costs of legislation and implementation of law are high. Thus, if the government regulates product quality in a way that reduces choice, there is a loss of freedom, which is a public good itself, since it cannot be denied to any consumer and is enjoyed by all consumers simultaneously (Cooter, 2000). In the case considered in this paper, regulating that all food be produced without pesticides constrains choice now and in the future since both conventional and organic produce are available currently in the market. Even a consumer with a high valuation of the attribute 'pesticide-free' will dislike the loss of future options.

This paper examines preferences for product quality regulations that involve the joint production of private and public goods. We consider the case of food safety regulation, as mandated by the Food Quality Protection Act (FQPA) of 1996, in which a mandated reduction in the use of agricultural pesticides increases the price of food, reduces individual health risk, reduces option value and enhances environmental quality. Our findings direct attention to the fact that public attitudes toward product quality regulations may derive from attitudes about both private and public goods.

\footnotetext{
${ }^{1}$ See Viscusi et al. (1988) on altruism and consumer safety regulations.
} 
We focus on pesticide regulation because its joint production nature is exceptionally clear. The majority of the public is aware of both the connections between pesticide residues and personal health and between pesticide use and environmental quality. It is well known that pesticide residues, particularly on fresh fruits and vegetables, pose health risks from cancer and other illnesses, and consumers are familiar with making market choices about the level of pesticide risk to which they and their families are exposed. At the same time, the adverse consequences of chemical inputs such as pesticides and fertilizers on fish and wildlife populations has been widely recognized since at least the publication of Rachel Carson's Silent Spring.

Working with a detailed in-person survey of consumers, we first characterize willingness to pay for an absence of pesticide residues on food, then examine support for government regulation of pesticide residues. A striking feature of the raw survey results, which is confirmed by more thorough econometric analysis, is that some individuals are not willing to pay a premium for pesticide-free food, but nonetheless support a ban on the use of pesticides in agriculture. This seemingly paradoxical result is explained by the fact that food quality regulation jointly produces both private and public goods: an individual with a strong preference for environmental quality but with little concern for personal health risk posed by pesticide exposure may well favor regulation of pesticide residues.

Another finding of the empirical analysis is that many individuals do not support the pesticide regulation even though they express a high willingness to pay for the absence of pesticide residues on their food. This result indicates that freedom of choice is also important, and that some consumers highly value preserving their future choices. In the status quo, these consumers are able to avoid pesticide residues by consuming organic produce. For them, the main benefit of the pesticide regulation is that consumption of pesticide-free food does nothing to change the level of environmental quality since one individual's impact on the total amount of pesticide use is miniscule. Thus, the regulation increases the level of one public good (environmental quality) but decreases the level of another (future freedom of choice).

The finding that joint production of public and private goods is a salient feature of product quality regulation raises the interesting possibility that individuals may support such interventions through voting or other means even though their consumption behavior suggests otherwise. This follows for two reasons. An individual may have a low willingness to pay for pesticide-free food, but care deeply about the environment. This voter may support the regulation even though she did not consume organic produce. Alternatively, a consumer may have a high willingness to pay for an absence of pesticide residues, but place a high option value on retaining future choices. This consumer may oppose the ban even though she has a track record of paying a premium for pesticide-free food, and may even have a high level of concern for the environment. Thus, referendum behavior may 
be a poor predictor of willingness to pay, and consumption behavior may be a poor predictor of support for public policies that change product quality.

The observation that consumption behavior may differ markedly from political behavior has implications for the use of techniques that infer the value of public interventions from consumer choices, and for methods that attempt to value public goods by examining referendum behavior. A common method employed in the environmental economics literature is to value regulations by examining consumer expenditures on avoidance goods, as in Blomquist (1979), Dardis (1980), Atkinson and Halvorsen (1990) and Dickie and Gerking (1997). ${ }^{2}$ For example, the value of a policy to reduce the incidence of skin cancer by strengthening the ozone layer might be deduced by aggregating expenditures on sunscreen, hats and other avoidance goods. Such a technique does not adequately address support for the regulation, since the public act of strengthening the ozone layer may have other effects. If the ozone layer is protected by reducing emissions of harmful chemicals, then there might be environmental quality improvements that are affiliated with the regulation, but not with the purchase of avoidance goods. Thus, using market choices to value the effect of protecting the ozone layer will misestimate the true level of support for the intervention. Similarly, it is clear from our estimation results that one would obtain a biased measure of the value of the FQPA by examining only market-based preferences for pesticide-free food.

The remainder of the paper in structured as follows. Section 2 develops a simple model of consumer preferences regarding market and voting choices for food quality in the context of pesticide residue avoidance. Section 3 describes our data and empirical methods. Section 4 presents estimation results from a survey of consumer preferences for pesticide reductions, and, in Section 5, concluding comments are provided.

\section{The value of food quality regulations: private and public goods}

The following model frames our study of individual preferences toward food quality regulations, and how these preferences compare to consumption behavior. Suppose an individual has an indirect utility function comprised of the following arguments: food prices $(P)$, health $(H)$, environmental quality $(N)$, and freedom of choice in consumption $(F)$. For analytic convenience, all other arguments in the

\footnotetext{
${ }^{2}$ See the survey by Viscusi (1996). Note also that the Dickie and Gerking study raised the possibility that regulations can jointly provide public and private goods.

${ }^{3}$ The same argument can be made about so-called 'travel cost' methods that measure the value of protecting some natural resource by the amount of money expended by individuals to recreate there. Again, government action to preserve a natural resource changes prices (and taxes), provides recreational opportunities, affects the level of environmental quality and constrains future choices.
} 
utility function are treated as exogenous factors and suppressed. These three arguments comprise a simple theoretical framework that nests an individual's willingness to pay (WTP) for food quality in a broader model of preferences for food quality regulation.

Let $\Delta P_{i}^{*}$ denote individual $i$ 's willingness to pay for the elimination of dietary pesticide residues, which we define as the value of the concomitant increase in health from a status quo level, $H_{i}^{0}$, to an augmented level, $H_{i}^{1}$. Normalizing initial food prices to one, this definition allows the WTP of an individual to be characterized as the solution to

$$
V_{i}\left(H_{i}^{1}, 1+\Delta P_{i}^{*}, F^{0}, N^{0}\right)=V_{i}\left(H_{i}^{0}, 1, F^{0}, N^{0}\right),
$$

where $V_{i}(\cdot)$ is the indirect utility function of individual $i$ and $F^{0}$ and $N^{0}$ are the status quo levels of option value and environmental quality. A linear approximation of the indirect utility function, evaluated at the indifference point defined by (1), yields

$$
\Delta P_{i}^{*}=-\frac{V_{H}}{V_{P}} \Delta H_{i},
$$

where $\Delta H_{i}=H_{i}^{1}-H_{i}^{0}$ denotes the health benefit gained by individual $i$ from eliminating pesticide residues in food consumption, and where $V_{H}$ and $V_{P}$ denote the marginal utility of health and the marginal utility of the price change, respectively. In (2), WTP depends on the perceived change in health from avoiding pesticide residues by consuming pesticide-free food, and on the scaling of this health effect by the ratio of marginal utilities of health and income.

Now, consider an individual's preference for a public policy eliminating pesticide residues on food. Food quality regulation that bans the use of pesticides may have four major effects on an individual: an income effect associated with the resulting change in food expenditure, a health effect gained through the elimination of pesticide residues on food, a loss of future consumption choices which implies a loss of option value, and an environmental quality effect from reduced chemical use in agriculture. Let $N^{1}$ denote the augmented state of environmental quality following a ban on pesticide use, let $F^{1}$ denote the reduced range of future consumption choices, and let $\Delta P_{i}$ denote the percentage change in food prices for individual $i$ as a result of the pesticide ban. Note that $\Delta P_{i}$ can differ from WTP, $\Delta P_{i}^{*}$, as defined in (2).

Now consider the voting decision on a referendum to ban pesticide use in agriculture. To begin, suppose that each individual votes for the proposal that gives the highest level of utility. Individual $i$ then favors a referendum to ban the use of pesticides if the utility level associated with a ban, $V_{i}\left(H_{i}^{1}, 1+\Delta P_{i}, F^{1}, N^{1}\right)$,

\footnotetext{
${ }^{4}$ The conceptual underpinnings of this approach are discussed by Deacon and Shapiro (1975).
} 
is above that of the status quo, $V_{i}\left(H_{i}^{0}, 1, F^{0}, N^{0}\right)$, and otherwise votes against such regulation. We can express the change in utility from the public policy by taking a linear expansion of indirect utility about the status quo equilibrium as follows:

$$
\mathrm{d} V_{i}=V_{H} \Delta H_{i}+V_{P} \Delta P_{i}+V_{F} \Delta F+V_{N} \Delta N
$$

where $\Delta N=N^{1}-N^{0}$ denotes the change in environmental quality that results from a decreased incidence of chemical use in food production, and $\Delta F=F^{1}-$ $F^{0}<0$ is the loss of consumption options.

Upon substitution of from (2), a manipulation of (3) results in

$$
\mathrm{d} V_{i}=-V_{P}\left\{\Delta P_{i}^{*}-\Delta P_{i}-\frac{V_{F}}{V_{P}} \Delta F-\frac{V_{N}}{V_{P}} \Delta N\right\} .
$$

In (4), the utility of individual $i$ increases with WTP for pesticide-free products and with the marginal utility of environmental quality, but decreases with the percentage change in food prices following the ban on pesticide use and decreases with the restriction on future consumption choices. Whether an individual supports or opposes the ban depends on the interplay of these factors.

If WTP exceeds the increased market price of food following the pesticide ban, then an individual will vote for the ban so long the value of lost freedom in consumption $\left(V_{F} \Delta F\right)$ does not more than offset his value of the environmental quality improvement $\left(V_{N} \Delta N\right)$. In general, an individual will vote for the ban so long as $V_{P}\left(\Delta P_{i}-\Delta P_{i}^{*}\right)+V_{F} \Delta F+V_{N} \Delta N \geq 0$. Thus, even an individual who values pesticide-free food less than the increase in expenditure required to purchase it (i.e., $\Delta P_{i}-\Delta P_{i}^{*} \geq 0$ ) may still vote for the pesticide ban so long as her valuation of the affiliated change in environmental quality, or $V_{N} \Delta N$, is sufficiently large. Conversely, an individual who does value pesticide-free food more than the increase in expenditure needed to purchase it will oppose the regulation if her valuation of preserving freedom of choices, or $-V_{F} \Delta F$, is sufficiently high.

An implication of this framework is that consumption behavior and voting behavior may be quite different. An individual will choose to purchase pesticidefree food whenever $\Delta P_{i}-\Delta P_{i}^{*} \leq 0$. Substituting for $\Delta P_{i}^{*}$ as defined by (2), it follows that an individual will consume pesticide-free food when $-V_{P} \Delta P_{i}-V_{H}$ $\Delta H_{i}<0$. As for the voting decision, it follows from the expression for the change in indirect utility associated with the pesticide ban that an individual will experience an increase in utility if $-V_{P} \Delta P_{i}-V_{H} \Delta H_{i} \leq V_{N} \Delta N+V_{F} \quad \Delta F$. Comparing these two expressions, we see that some individuals may choose not to consume pesticide-free food, but will still vote to ban the use of pesticides in agriculture. Thus, WTP and referendum choices are not the same, and individuals' market and political behavior may differ depending on their characteristics.

This basic framework can be applied to other product quality regulations. Consider the case of a regulation on production methods such a prohibition on child labor or on incidental killing of dolphins to harvest tuna. In this situation, the 
market price of the good will increase following a ban on the offensive production technique, future options will shrink, and the level of some public good will increase (e.g., child welfare or the level of the dolphin population). Note, however, that the regulation will not affect a private good analogous to health in the pesticide example (i.e., $\Delta H_{i}=0$ ). That is, the 'regulated' product is identical to the original product from the consumer's point of view. In this case, individuals would not freely consume a product produced by an alternative method due to the free-rider problem because they perceive that their consumption choices have no effect on the level of provision of the public good.

However, as long as an individual values freedom and the affiliated public good (i.e., as long as $V_{F} \Delta F+V_{N} \Delta N \geq 0$ ), then they may well vote for the ban on the offensive production technique. In particular, an individual will favor the ban whenever $-V_{P} \Delta P_{i} \leq V_{F} \Delta F+V_{N} \Delta N$.

Conversely, if there is no public good impact associated with a product quality regulation, then $\Delta N=0$ in (4). In this case, voting choices may be even more different than market choices since the regulation involves the loss of one public good (future consumption choices) without the offsetting increase in another (environmental quality). Not surprisingly, such referenda are rare, since the market provides an efficient amount of the desirable product quality and public intervention is not needed.

\section{Empirical analysis}

The conceptual model of Eqs. (2) and (4) can be expressed in the following recursive form that is convenient for estimation:

$$
\begin{aligned}
& \mathrm{WTP}_{i}=\alpha+\beta X_{i}+\varepsilon_{i} \\
& \text { Vote }_{i}=\gamma+\delta \mathrm{WTP}_{i}+\phi Y_{i}+\eta_{i},
\end{aligned}
$$

Estimation of the voting equation must account for the fact that WTP is endogenous. It is also informative to compare the coefficients between the two regressions to see how demographic factors affect WTP and voting.

Eq. (5) is based on the assumption that $\mathrm{WTP}_{i}$ is a linear function of exogenous variables, $X_{i}$. These variables are primarily household, demographic and ethnic characteristics that may influence voting. The coefficients $\alpha$ and $\beta$ are unknown, and $\varepsilon_{i}$ is an error term. Following Eq. (4), the estimated voting Eq. (6) supposes that an individual's preference for a ban on pesticide use is a function of the utility difference between alternatives.

Exogenous factors, denoted as $Y_{i}$, and stated WTP are hypothesized to explain voting choices. Included in the matrix $Y_{i}$ is an individual's stated level of concern 
for the environment, which is a public good affected by pesticide use. ${ }^{5}$ Personal characteristics are also related to attitudes about government restriction of choice. The effect of variation in option value is embedded in the coefficients on exogenous factors. The parameters $\gamma, \delta$ and $\phi$ are unknown and is an error term.

Estimation of the WTP Eq. (5) is carried out using standard, left-censored Tobit since responses are truncated at 0 . Estimation of the voting Eq. (6) must account for the fact that WTP is endogenous. To estimate the parameters of the voting equation, we use Probit with instrumental variables (Maddala, 1983); estimated WTP from (5) is used as the instrument. ${ }^{6}$ Identification is ensured since some explanatory variables are excluded from the voting equation. We describe the data and choice of regressors shortly.

The data requirements of this model pose another problem: how an individual votes on a particular food quality regulation is private information. Consequently, we derive our sample from survey data. The sampling frame is comprised of residents of the Greater Bay Area and Central Valley of California, an area where consumers have experience with voting on food quality and environmental quality regulations. A total of 233 in-person surveys were conducted at supermarket produce counters. To reflect the bilingual nature of many Bay Area cities, $10 \%$ of the surveys were administered in Spanish. Each individual was asked to state his or her WTP for pesticide-free food and to describe how he or she would vote on a referendum measure to ban the use of pesticides to produce food. Interviewers also collected information on household demographics and food consumption patterns.

Nearly all of the 17 survey locations represented in our sample (including major chains - especially Safeway, which dominates the local market) offer both conventional and organic produce, and pesticide-free food is also available from specialty stores and farmers' markets. The notion of pesticide-free food is quite real to most food shoppers, and those in our sample had the opportunity to observe actual price differentials between conventional and organic produce. Since these price differentials should be representative of the price impacts of the pesticide ban, it is reasonable to assume that consumers have informed perceptions about the cost of the referendum.

The survey collected information on various individual and household characteristics. Respondents were queried about whether they would vote for a referendum measure to ban pesticide use in agriculture, and also about their willingness to pay to avoid pesticide residues on food (i.e., WTP for pesticide-free food). WTP is expressed in percentage terms (e.g., a percentage increase in food prices). These dependent variables were regressed on a collection of variables representing household characteristics and consumption behavior.

Respondents were asked to state their level of concern for the environment,

\footnotetext{
${ }^{5}$ This utility-difference framework for estimating a voting equation is similar to that of Deacon and Shapiro (1975), Bergstrom et al. (1988) and Hoyt and Lee (1998).

${ }^{6}$ Uncorrected WTP, or $\mathrm{WTP}_{i}=\hat{\alpha}+\hat{\beta} X_{i}$, is used as the instrument.
} 
which we measure as a discrete $(0 / 1)$ variable. Educational attainment was also measured as a dummy variable: respondents were asked if anyone in their household had attained a 4-year college degree. Smoking has well-documented health effects, and we therefore asked respondents how many packs of cigarettes they consumed per day.

Next, survey respondents were asked how many children were living in the household, if any. They were also asked to report their household's weekly food expenditure. This variable was measured continuously, and respondents were asked to report only expenditure on food prepared at home (i.e., bought from a store and consumed at home) and to exclude expenditures on meals eaten away from home. Respondents were also asked about their level of household income. We asked respondents to report income in ranges to reflect the fact that most individuals do not have precise information on their level of household income, and also to avoid being too invasive. Income was grouped into three classes (low, medium and high) and measured by two dummy variables (one for low income and one for high income). Low income was considered to be a household income of less than $\$ 20000$, and high income was considered to be an income of more than $\$ 50000$.

Finally, we asked respondents to state which racial group they most identify with (Caucasian, African-American, Latino, Asian-American or Other). Results were measured by a set of discrete variables, with Caucasian being the reference group. Respondents were also asked to state their gender. Male was chosen as the reference group, so women were given a value of 1 for this variable.

Of those surveyed, $40.34 \%$ were in favor of the proposed pesticide regulation, a finding that is consistent with the results of California's Proposition 128 initiative in 1990 where nearly $40 \%$ of the population voted to prohibit the use of broad classes of pesticides in agriculture. Fig. 1 compares the frequency distribution of WTP responses among individuals who voted for the pesticide ban to that among

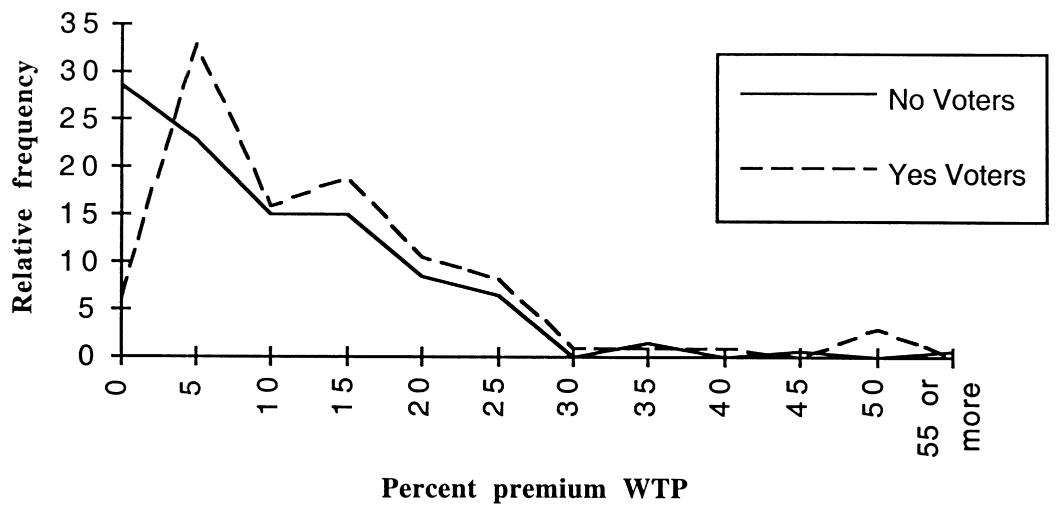

Fig. 1. WTP responses for subgroups voting for and against the proposed ban. 
individuals who unfavorably viewed the proposal. Generally, those consumers expressing support for the ban had a higher percent willingness to pay for pesticide-free food. However, one interesting result from this graphical analysis is that some individuals expressed support for the referendum measure but stated no willingness to pay for pesticide-free food. While not conclusive, this evidence suggests that, to some individuals at least, voting is perceived to affect more than just product quality.

Another significant result, which follows directly from Fig. 1, is that some individuals expressed high WTP for pesticide-free food, but still opposed the pesticide ban. This observation is consistent with our premise that consumers value preserving their freedom of choice. Their reasoning may be option-theoretic. That is, consumers may understand that regulation changes slowly, and realize that even if they are willing to pay to consume entirely organic produce today, that they may wish to make other choices in the future. Or, some consumers could simply resent government intrusion into this aspect of their lives.

Table 1 shows the correlation matrix for the voting preference on pesticide regulation (where a favorable response takes unitary value), the expressed WTP to avoid pesticide residues in food consumption, and the various exogenous decision factors employed in the model. Notice that the correlation between WTP to eliminate pesticide residues on food and a favorable vote on pesticide regulation is positive, but small relative to the correlation between voting choice and other variables. A favorable view of a pesticide ban is more strongly correlated with children in a household and with environmental concern than with WTP for eliminating pesticide residues on food.

Not surprisingly, income is significantly related to environmental concern in the sample, as low (high) income respondents view environmental protection to be less (more) important than do middle income individuals. In addition, there is a positive correlation between children in a household and concern for the environment, which is consistent with the bequest motives associated with environmental preservation.

The education level of the highest-educated household member is positively correlated with household income, but negatively correlated with children in the household. There is also a strong negative correlation between education and cigarette consumption, which is consistent with the finding of Kenkel (1990) that educational attainment has a positive influence on personal health.

Interestingly, the majority of demographic factors in Table 1 influence WTP and voting behavior in an opposing fashion. For example, education is negatively correlated with a favorable vote on pesticide regulation but positively correlated with WTP, and children in a household is positively correlated with a preference to ban pesticides but negatively correlated with WTP. Household income below a baseline middle-income level is positively correlated with a favorable view of pesticide regulation but negatively correlated with WTP, with the converse holding for relatively high-income households. 
Table 1

Regressor correlation matrix

\begin{tabular}{|c|c|c|c|c|c|c|c|c|c|c|c|c|c|c|}
\hline & Ban & WTP & $\begin{array}{l}\text { Enviro- } \\
\text { nment }\end{array}$ & $\begin{array}{l}\text { Educa- } \\
\text { tion }\end{array}$ & Smoking & Children & Exposure & Female & Black & Latino & Asian & Other & $\begin{array}{l}\text { Low } \\
\text { income }\end{array}$ & $\begin{array}{l}\text { High } \\
\text { income }\end{array}$ \\
\hline Ban & 1 & & & & & & & & & & & & & \\
\hline WTP & 0.17 & 1 & & & & & & & & & & & & \\
\hline Environment & 0.23 & 0.14 & 1 & & & & & & & & & & & \\
\hline Education & -0.07 & 0.19 & 0.12 & 1 & & & & & & & & & & \\
\hline Smoking & -0.10 & -0.18 & -0.25 & -0.25 & 1 & & & & & & & & & \\
\hline Children & 0.24 & -0.10 & 0.12 & -0.06 & -0.03 & 1 & & & & & & & & \\
\hline Female & 0.19 & 0.16 & 0.26 & 0.11 & 0.26 & 0.07 & 0.06 & 1 & & & & & & \\
\hline Black & 0.17 & 0.13 & -0.05 & -0.22 & -0.05 & 0.05 & -0.03 & -0.13 & 1 & & & & & \\
\hline Latino & 0.08 & -0.15 & -0.17 & -0.21 & 0.09 & 0.13 & 0.17 & -0.07 & n.a. & 1 & & & & \\
\hline Asian & -0.16 & 0.01 & 0.01 & 0.09 & 0.06 & -0.04 & -0.12 & 0.01 & n.a. & n.a. & 1 & & & \\
\hline Other & 0.11 & 0.08 & 0.12 & -0.04 & -0.02 & 0.07 & 0.11 & -0.04 & n.a. & n.a. & n.a. & 1 & & \\
\hline Low income & 0.04 & -0.13 & -0.06 & -0.22 & 0.09 & -0.04 & -0.15 & -0.05 & 0.17 & 0.14 & -0.03 & 0.09 & 1 & \\
\hline High income & -0.02 & 0.09 & 0.13 & 0.41 & -0.16 & 0.07 & 0.06 & 0.07 & -0.12 & -0.21 & 0.05 & -0.12 & n.a. & 1 \\
\hline
\end{tabular}




\section{Results}

\subsection{Willingness to pay}

Results of the Tobit estimation of (5) are presented in the first column of Table 2. Education, gender, low income, and African-American and 'other' ethnicity are positively associated with stated percent willingness to pay for the food quality attribute 'pesticide-free' at conventional levels of significance. Household food expenditure, low income and cigarette consumption are negatively associated with WTP.

The sign of the coefficient on the low-income group conforms to the predicted relationship, as marginal utility of income influences WTP inversely in (2). Expression (2) also indicates that high-income respondents have greater WTP. The lack of significance of this coefficient is not particularly surprising, however, given the diminishing marginal utility of income. The negative sign of the coefficient on household food expenditure suggests that WTP is concave with respect to household food expenditure.

The coefficient on children is negative, but insignificant. This result may seem surprising in light of the recent evidence that indicates greater sensitivity to pesticide residues among children than adults (see National Academy of Sciences, 1993), but is explained by several countervailing factors. Life-cycle models of health demand (for example, Arthur, 1981; Cropper and Sussman, 1988) find age to be a theoretically important determinant of WTP that decreases the value of avoiding long-term health risks, a result that suggests a positive association between children in a household and WTP. Individuals with children purchase food for members of a household that are younger, on average, than in households without children. However, per capita income also declines in the sample as family size increases, which tends to make pesticide-free produce relatively more expensive for larger households. Cropper and Sussman (1988) also find families with children to have significantly higher discount rates, which would reduce the costs associated with long-term decrements in health.

Not surprisingly, the coefficient on cigarette consumption is negative and significant in the WTP equation. The consumption of cigarettes is likely to be inversely related to the perceived change in health from reduced exposure to pesticide residues and may also indicate a greater willingness to accept latent health hazards. The long-term health effect associated with the elimination of pesticide residues may be perceived as having only limited effectiveness for individuals not supplementing health in other dimensions. The sign and significance of this coefficient indicates that personal health motivations are an important determinant of an individual's willingness to pay to eliminate pesticide residues on food.

Education is linked to greater percent willingness to pay for pesticide-free food. This finding suggests that educated individuals may more adequately realize causal links between pesticide residues and latent health effects. Education has been 
Table 2

Estimation results

\begin{tabular}{|c|c|c|}
\hline & WTP & Vote \\
\hline Intercept & $\begin{array}{l}0.0174 \\
0.5310\end{array}$ & $\begin{array}{c}-2.9707 * \\
0.6833\end{array}$ \\
\hline Children & $\begin{array}{r}-0.0001 \\
0.0173\end{array}$ & $\begin{array}{l}0.4664^{*} \\
0.2153\end{array}$ \\
\hline $\begin{array}{l}\text { Household food } \\
\text { expenditure }\end{array}$ & $\begin{array}{c}-0.0004 * \\
0.0002\end{array}$ & $\begin{array}{l}0.0021 \\
0.0022\end{array}$ \\
\hline Education & $\begin{array}{l}0.0453^{*} \\
0.0166\end{array}$ & $\begin{array}{r}-0.0921 \\
0.2111\end{array}$ \\
\hline $\begin{array}{l}\text { Concern for } \\
\text { environment }\end{array}$ & $\begin{array}{l}0.0178 \\
0.0114\end{array}$ & $\begin{array}{l}0.3890 * \\
0.1442\end{array}$ \\
\hline Female & $\begin{array}{l}0.0298 * \\
0.0151\end{array}$ & $\begin{array}{l}0.3978 * \\
0.1925\end{array}$ \\
\hline Black & $\begin{array}{l}0.0793 * \\
0.0198\end{array}$ & $\begin{array}{l}0.5668 * \\
0.2491\end{array}$ \\
\hline Asian & $\begin{array}{l}0.0199 \\
0.0215\end{array}$ & $\begin{array}{r}-0.4351 \\
0.2878\end{array}$ \\
\hline Latino & $\begin{array}{l}0.0203 \\
0.0261\end{array}$ & $\begin{array}{l}0.6683^{*} \\
0.3153\end{array}$ \\
\hline Other & $\begin{array}{l}0.0909 * \\
0.039\end{array}$ & $\begin{array}{l}0.4849 \\
0.4673\end{array}$ \\
\hline Low income & $\begin{array}{c}-0.0581 * \\
0.0186\end{array}$ & $\begin{array}{l}0.1289 \\
0.2367\end{array}$ \\
\hline High income & $\begin{array}{r}-0.0015 \\
0.0191\end{array}$ & $\begin{array}{r}-0.0103 \\
0.2416\end{array}$ \\
\hline Smoking & $\begin{array}{c}-0.0383 * \\
0.0176\end{array}$ & \\
\hline WTP & & $\begin{array}{l}2.5058 * \\
0.9431\end{array}$ \\
\hline Scale & $\begin{array}{l}0.1068 \\
0.0054\end{array}$ & \\
\hline $\begin{array}{l}\text { Log likelihood } \\
\text { Observations } \\
\% \text { Correct }\end{array}$ & $\begin{array}{l}134.41 \\
233\end{array}$ & $\begin{array}{c}-130.68 \\
233 \\
78\end{array}$ \\
\hline
\end{tabular}

*Significance at the $5 \%$ level or below.

found to be significantly related to health-improving activities in a number of other studies.

\footnotetext{
${ }^{7}$ In addition to the Kenkel study cited earlier, Blomquist (1979) found that individuals with college education are more likely to engage in precautionary behavior (i.e., wearing seat belts) to avoid injury in automobile accidents.
} 
Basic demographic factors are also systematically related to WTP. There is a strong relationship between gender, ethnicity and the stated value of avoiding pesticide residues. On average, women in the sample have a higher willingness to pay than men do, and African-Americans and members of the 'other' ethnic group have a higher WTP than Caucasians. Similar relationships between ethnic identification, gender and willingness to pay to avoid health risks have been documented in other economic studies (Blomquist, 1979; Viscusi et al., 1988; Krupnick and Cropper, 1992).

Finally, it is interesting to note that the coefficient on environmental concern was insignificant in the WTP regression. This finding indicates that individuals understand the distinction between their personal consumption choices and the provision of environmental quality. In the uncorrected correlation analysis, environmental concern is somewhat correlated with WTP. However, this relationship becomes insignificant after controlling for consumption behavior and demographic characteristics. Willingness to pay for pesticide-free food appears to be a based on an individual's valuation of personal health rather than a statement about the importance of the environment. In this sense, individuals understand that purchasing pesticide-free produce is not a political act.

\subsection{Voting behavior}

The second column of Table 2 reports the estimates of Eq. (6). Overall, the discrete choice model fits the data well, correctly classifying over $77 \%$ of the responses. Children, environmental concern, gender, African-American ethnicity and willingness to pay for pesticide-free food increase the likelihood of support for the pesticide regulation; the coefficients on these variables are all significant at the $5 \%$ level. ${ }^{8}$ Smoking is excluded from the voting equation for two reasons. From a theoretical point of view, in Eq. (4), the utility difference from the pesticide ban does not include $V_{H}$ or $\Delta H_{i}$, which are the primary factors in the model that are influenced by smoking, since health effects are subsumed in WTP. From a practical point of view, excluding smoking from the voting equation also ensures identification of (6).

As predicted by the conceptual model, willingness to pay to avoid pesticide residues is positively associated with a willingness to support the pesticide

\footnotetext{
${ }^{8}$ Note that the intercept is also negative and significant. Part of this coefficient may reflect voters' dislike for restrictions on freedom of choice in the marketplace.

${ }^{9}$ It should be noted that a in 'naïve' regression estimating voting as a function of all variables, the coefficient on smoking was insignificant, having a $P$ value of 0.5 . If individuals who smoke not only place lower values on consumption of pesticide-free food, but also have different views of the value of a clean environment, than their non-smoking neighbors, then the smoking variable may not be a valid instrument.
} 
regulation, and is highly significant. Thus, individual valuation of the food-quality attribute 'pesticide-free' clearly influences the voting decision.

The coefficient on WTP is not the only significant variable in the estimated voting choice equation, however. This finding suggests that, as expected, private valuations of food quality improvements do not completely determine individual preferences for food quality regulation. As predicted by the conceptual model, stated level of concern for the environment increases the likelihood that an individual will support the pesticide ban. The incentive to provide public goods such as environmental quality through collective choices appears to be an important source of value of food quality regulations. Further, it is important, and consistent with the theoretical model, that environmental concern was insignificant in the WTP equation, but highly significant in the voting equation. This finding clearly supports the hypothesis that different factors influence the consumption and voting decisions.

Concern for the environment raises the amount that an individual would be willing to pay for product quality regulation above and beyond the value of the private benefits from the regulation. To quantify this effect, note that the estimated coefficients imply that a $1 \%$ increase in WTP increases the likelihood of voting for the referendum by $2.5 \%$. Since a high level of environmental concern increases the likelihood of supporting the referendum by $39 \%$, then the impact of concern for environmental quality is equivalent to a $16 \%$ increase in WTP for pesticide-free food $(0.39 / 0.025=16)$. These estimates suggest that environmental-leaning individuals value the regulation by $16 \%$ times their food expenditure because of the environmental effect alone. This amount must be added to the amount of WTP to obtain a true measure of the value of the regulation..$^{10}$

As in the WTP equation, demographic characteristics also influence the voting decision. ${ }^{11}$ For example, the number of children in the household is significantly related to support for the referendum. This finding is consistent with the bequest motive for environmental concern since individuals may wish their children to inherit a high level of environmental quality. Similar findings related to the influence of children on valuation have been reported by Cropper and Sussman (1988), among others.

Latino ethnicity is positively associated with a favorable view of pesticide

\footnotetext{
${ }^{10}$ Future research should attempt to obtain explicit estimates of the effect of preferences for unrestricted choice on preferences for the regulation.

${ }^{11}$ The working assumption behind the survey and the econometric model is that all individuals in the sample would observe the same price changes resulting from the pesticide regulation, and thus $\Delta P_{i}$ would be the same for all individuals. However, it is possible that even though market prices will be the same for all consumers after the pesticide ban, individuals may have different perceptions of the impacts of the ban ex ante. These perceptual differences may be embedded in the demographic and consumption variables in the coefficients. It is difficult to explain why women or African-Americans, for example, would expect lower price impacts of the regulation (and thus higher propensity to vote for the ban) than would other groups. Nonetheless, this effect may partly explain the pattern of estimates.
} 
regulation, but is an insignificant determinant of WTP. The proclivity of Latino respondents to favor pesticide controls is interesting, especially since Latino ethnicity and environmental concern are negatively correlated in Table 1. It is possible that this finding reflects the fact that the vast majority of farm workers in California (who are routinely exposed to pesticides, as described in Sunding and Zivin (2000)) are from Mexico and other Latin American countries. Latino respondents in the San Francisco Bay Area may identify with this group of workers, either because they themselves have worked in agriculture, or because they have friends and relatives employed there. Thus, the positive coefficient may suggest that the provision of other public goods such as the welfare of field workers may be important when considering preferences toward pesticide regulations. We do not press the point here, because we have only the most fragmentary data on these relationships, but Latino respondents may be more sensitive to worker safety issues in agricultural production than are other ethnic groups. Viscusi et al. (1988) have documented the existence of similar altruism effects with respect to other risk reduction measures.

Household income level does not influence the voting decision, independent of the other explanatory variables. Both income coefficients are insignificant, although they are of opposite sign. Interestingly, income does have a systematic effect on WTP, as demonstrated by the estimation of (5). This is evidence, albeit indirect, that different factors are at play in the consumption and voting decisions. Similarly, household food expenditures are negatively associated with WTP, but have an insignificant relationship to support for the referendum.

\section{Conclusion}

The paper explores the factors determining support for public policies that regulate the level of product quality. Our main hypothesis is that product quality regulations can affect consumer welfare in four ways: by increasing market price, by increasing the provision of some desirable attribute of the product, by restricting consumer freedom and by affecting the provision of other, affiliated public goods. For example, regulation that requires imported tuna to be 'dolphinsafe' enhances the dolphin population and the promotion of 'free-range' poultry or cosmetics that are not tested on animals reduces the incidence of animal cruelty. Even the recent effort by manufacturers such as Nike, Reebok and K-Mart to ensure consumers that their products are made without the use of child or sweatshop labor affects the level of public goods.

The paper develops a conceptual model of product quality regulations that includes impacts on public goods (in particular the range of consumer choice and environmental quality), and applies the framework to the case of the Food Quality Protection Act of 1996 that limits allowable levels of pesticides on food by restriction the use of pesticides in agriculture. This regulation will change relative 
prices, improve food safety and provide public goods in the form of enhanced fish and wildlife populations.

An interesting implication of this framework is that consumption behavior and voting behavior may be quite different. In particular, an individual may rationally express no WTP for pesticide-free food, but still express support for a referendum measure banning pesticide use. Personal consumption choices do not influence the level of public goods since an individual has a miniscule effect in the market. However, a public policy to ban pesticide use will influence environmental quality, and if the individual cares enough about this public good, then she may support the pesticide ban even if her WTP for pesticide-free food is less than the actual price difference between conventional and organic produce. Thus, WTP and referendum choices are not the same, and individuals' market and political behavior may differ depending on their personal characteristics.

Further, an individual may express high WTP for pesticide-free food and a high level of concern for the environment, both factors that would tend to predict support for the regulation, yet still oppose the referendum if they dislike longlasting restrictions on consumption choices. That is, even individuals who have 'green' proclivities may still oppose the ban if they resent the government limiting their future options.

An econometric model is specified to estimate support for the pesticide ban, taking account of the fact that WTP for pesticide-free food is endogenous. Estimation is carried out using data from a survey of food shoppers in the Greater San Francisco Bay Area. Each individual was asked to state his or her WTP for pesticide-free food and to describe how he or she would vote on a referendum measure to ban the use of pesticides to produce food. Interviewers also collected information on household characteristics and food consumption patterns.

Results of the WTP estimation are consistent with the conceptual model, and with the findings of other studies of avoidance expenditures. Education, gender, low income, and African-American and 'other' ethnicity are positively associated with WTP for the food quality attribute 'pesticide-free' at conventional levels of significance. Household food expenditure, low income and cigarette consumption are negatively associated with WTP.

As predicted by the conceptual model, willingness to pay to avoid pesticide residues is positively associated with a willingness to support the pesticide regulation, and is highly significant. Thus, individual valuation of the food-quality attribute 'pesticide-free' clearly influences the voting decision. The coefficient on WTP is not the only significant variable in the estimated voting choice equation, however, and private valuations of food quality improvements do not completely determine individual preferences for food quality regulation. As predicted by the conceptual model, a high level of concern for the environment increases the likelihood that an individual will support the pesticide ban. The incentive to provide public goods such as environmental quality through collective choices is an important source of value of the pesticide regulation. 
Our study provides evidence that a potentially significant disparity exists between the value of marketable attributes of product quality and the value of product quality regulations. Support for a referendum measure is a poor proxy of willingness to pay, and a poor measure of the value of the affiliated public good of environmental quality. Thus, care must be exercised in attempts to infer the value of risk-reduction policies from private aversion activities or other individual actions. Consumer preferences for product quality regulations may reflect not only the value of these private benefits, but also the additional benefits associated with the provision of public goods. Similarly, care must also be exercised when attempting to infer the value of public goods from referendum choices since public action may affect the level of public goods as well as ones that can be provided by the market.

\section{Acknowledgements}

This research was sponsored by the US Environmental Protection Agency and the California Department of Food and Agriculture. The opinions expressed here do not necessarily reflect those of the funding agencies. The authors thank George Judge, Theodore Keeler, Ethan Ligon, Jeff Perloff, and Elisabeth Sadoulet, as well as seminar participants at UC Berkeley, UC Santa Barbara, Hebrew University, Iowa State University, University of Maryland and Stanford University. National Research Council, Committee on Pesticides in the Diets of Infants and Children. Pesticides in the Diets of Infants and Children, Washington, DC. National Academy Press, 1993. Sunding and Zilberman are members of the Giannini Foundation of Agricultural Economics.

\section{References}

Arthur, W., 1981. The economics of risks to life. American Economic Review 71, 54-64.

Atkinson, S., Halvorsen, R., 1990. Evaluation of risks to life: evidence from the marketplace for automobiles. Review of Economics and Statistics 72, 133-136.

Bergstrom, T., Roberts, J., Rubinfeld, D., Shapiro, P., 1988. A test for efficiency in the supply of public education. Journal of Public Economics 35, 289-307.

Blomquist, G., 1979. Value of life saving: implications of consumption activity. Journal of Political Economy 87, 540-558.

Cooter, R., 2000. In: The Strategic Constitution. Princeton University Press, Princeton.

Cropper, M., Sussman, F., 1988. Families and the economics of risks to life. American Economic Review 78, 255-260.

Dardis, R., 1980. The value of a life: new evidence from the marketplace. American Economic Review 70, 1077-1082.

Deacon, R., Shapiro, P., 1975. Private preference for collective goods revealed through voting on referenda. American Economic Review 65, 943-955. 
Dickie, M., Gerking, S., 1997. Genetic risk factors and offsetting behavior: the case of skin cancer. Journal of Risk and Uncertainty 15, 81-97.

Hoyt, W., Lee, K., 1998. Educational vouchers, welfare effects, and voting. Journal of Public Economics 69, 211-228.

Kenkel, D., 1990. Consumer health information and the demand for medical care. Review of Economics and Statistics 72, 587-595.

Krupnick, A., Cropper, M., 1992. The effect of information on health risk valuations. Journal of Risk and Uncertainty 5, 29-48.

Maddala, G., 1983. In: Limited-dependent and Qualitative Variables in Econometrics. Cambridge University Press, Cambridge.

Sunding, D., Zivin, J., 2000. In: Comparison of Policies to Reduce Workplace Injuries from Toxic Substances: The Case of Pesticide Poisoning of Farmworkers. Department of Public Health, Columbia University School of Medicine.

Viscusi, W., 1996. Economic foundations of the current regulatory reform efforts. Journal of Economic Perspectives 10, 119-134.

Viscusi, W., Magat, W., Forrest, A., 1988. Altruistic and private valuations of risk reduction. Journal of Policy Analysis and Management 7, 227-245. 